\title{
Land consumption and income in Italy: a case of inverted EKC
}

This is the peer reviewed version of the following article:

Original:

Bimonte, S., Stabile, A. (2017). Land consumption and income in Italy: a case of inverted EKC.

ECOLOGICAL ECONOMICS, 131, 36-43 [10.1016/j.ecolecon.2016.08.016].

Availability:

This version is availablehttp://hdl.handle.net/11365/1000570

since 2016-11-23T16:48:28Z

\section{Published:}

DOI:10.1016/j.ecolecon.2016.08.016

Terms of use:

Open Access

The terms and conditions for the reuse of this version of the manuscript are specified in the publishing policy. Works made available under a Creative Commons license can be used according to the terms and conditions of said license.

For all terms of use and more information see the publisher's website.

(Article begins on next page) 


\section{Manuscript Details}

\section{Manuscript number}

Title

Article type
ECOLEC_2016_211

Land consumption and income in Italy

A case of inverted EKC

Research paper

\section{Abstract}

The EKC hypothesis postulates that the relationship between economic growth and environmental deterioration is represented by an inverted U-shaped function. Its validity has been questioned from several perspectives and a need for public policies has been expressed. This paper uses a heuristic approach to analyze the relationship between per capita income and land consumption, as proxied by the number of Building Permits issued by public authorities. Using data from the Italian regions, we run a panel data regression model to test whether the EKC hypothesis holds. Results confute it, evidencing a U-shaped relationship. In the authors' opinion, the combined effect of market conditions, lifestyle evolution and institutional and political factors have produced an adverse effect on environment. On this basis, the paper claims that, when social and intergenerational aspects are involved, a balanced mix of market, policies and institutional architecture is needed.

Keywords

Manuscript category

Corresponding Author

Corresponding Author's

Institution

Order of Authors

Suggested reviewers
Environmental Kuznets Curve; Urban development; Land use; Soil sealing; Housing

Analysis

Salvatore Bimonte

University of Siena

Salvatore Bimonte, Arsenio Stabile

Lionello Punzo, JUAN GABRIEL BRIDA, EDGAR CARRERA

\section{Submission Files Included in this PDF}

\section{File Name [File Type]}

ICI_EKC_ECO.docx [Manuscript]

Title page.doc [Title page]

Response to reviewers.docx [Response to reviewers]

Highlights.doc [Highlights]

Letter to editor.docx [Cover Letter]

To view all the submission files, including those not included in the PDF, click on the manuscript title on your EVISE Homepage, then click 'Download zip file'. 


\title{
LAND CONSUMPTION AND INCOME IN ITALY \\ A CASE OF INVERTED EKC
}

\begin{abstract}
The EKC hypothesis postulates that the relationship between economic growth and environmental deterioration is represented by an inverted U-shaped function. Its validity has been questioned from several perspectives and a need for public policies has been expressed. This paper uses a heuristic approach to analyze the relationship between per capita income and land consumption, as proxied by the number of Building Permits issued by public authorities. Using data from the Italian regions, we run a panel data regression model to test whether the EKC hypothesis holds. Results confute it, evidencing a U-shaped relationship. In the authors' opinion, the combined effect of market conditions, lifestyle evolution and institutional and political factors have produced an adverse effect on environment. On this basis, the paper claims that, when social and intergenerational aspects are involved, a balanced mix of market, policies and institutional architecture is needed.
\end{abstract}

Keywords: Environmental Kuznets Curve, Urban development; Land use; Soil sealing, Housing. JEL Classification: C23; H71; Q24; Q56; R31; R38.

\section{Introduction}

The decreasing capacity of our planet to support life is the major concern of the third millennium. It depends on the scarcity of the environment as a whole, regarded as a resource made up of many different resources. Land (and fertile topsoil) is among the most important, being an essential element of all ecosystems and at the same time of construction and food production. Although privatized, it has the characteristics of commons or public goods, as well as representing a good whose utilization produces externalities. Its management is therefore normally under public control. In fact, urban planning is a key policy of public authorities, in particular local government. The latter should manage it in order to maximize social welfare. Specifically, in deciding changes in land use, policy makers should appraise various needs (social, economic) in term of their opportunity cost (environmental degradation). Economic development has largely determined land use changes and degradation. The two phenomena are strongly correlated.

Since the 1990s, many studies have investigated the relationship between economic growth and environmental quality. A considerable number of studies fall in the empirical line of investigation known as the Environmental Kuznets Curve (EKC), according to which the relationship between environmental quality and per capita GDP may be represented by a quadratic (inverted U-shaped), sometime cubic (N-shaped), function (Grossman and Krueger, 1995; Torras and Boyce, 1998). Through a deterministic sequence of phases, environmental quality initially deteriorates, improving once per capita income passes a certain threshold.

Empirical studies test the EKC-hypothesis using a general reduced-form model that measure directly the impact of income on environmental degradation. Attempts have been made to 
theoretically anchor and interpret this process (Dasgupta et al., 2002; Kriström and Riera, 1996; Lopez, 1994; McConnel, 1997; Munasinghe, 1999). Empirical analyses have been carried out to determine which structural or socioeconomic variables, other than income, may influence it (Balaguer and Canavella, 2016; Bimonte, 2002; Grossman, 1995; Grossman and Krueger, 1995, 1996; Magnani, 2000; Panayotou, 1995; Selden and Song, 1994; Suri and Chapman, 1998; Unruh and Moomaw, 1998).

However, the relevant empirical evidence is not very clear-cut. In fact, while some empirical studies support the EKC hypothesis, others are not completely consistent with it (Bagliani, et al., 2008; Caviglia-Harris et al., 2009; Harbaugh et al., 2002; Shafik and Bandyopadhyay, 1992; Stern and Common, 2001; Stern, et al., 1996). There is evidence that environmental pressure intensifies as per capita income increases. York et al. (2004) and Caviglia-Harris et al. (2009) emphasize that ecological footprint rises significantly with per capita GDP so does land degradation (Salvati and Zitti, 2008). In general, it seems that the EKC may hold for some groups of countries or environmental indicators (especially local pollutants) (Lopez, 1994), but not for all (World Bank, 1992). ${ }^{1}$ It may also hold for some countries to the detriment of others (Aşici and Acar, 2016; Kearsley and Riddel, 2010).

These studies normally test the environmental pressure in terms of per capita or per dollar emissions/concentrations (intensity of use) of a particular pollutant (e.g. SO2, CO2 or particulates); yet other researches use composite indexes of environmental degradation (Panayotou, 2003). ${ }^{2}$ To the best of our knowledge, no one has investigated the EKC for land consumption. Land (and topsoil) is at the root of all human activities, especially food production and building of infrastructure. According to the European Soil Charter "soil is one of humanity's most precious assets. It allows plants, animals and man to live on the earth's surface” (Council of Europe, 1972).

Land is a limited resource and soil is slowly renewable. Urbanization is a major cause of soil degradation and land consumption (EEA and JCR, 2010). Among the various, housing, especially residential, represents the principal form of construction. There is evidence of a strong correlation between urbanization, population and income growth (Jedwaba and Vollrathb, 2015). Therefore, also to develop the more appropriate policy prescriptions, we think that understanding this relationship is of utmost interest.

Approaching the issue from an EKC perspective, in this paper we test the relationship between per capita income and per capita land consumption, as proxied by the number of building permits (BP) annually issued by local authorities. The latter are strongly related with new housing supply (Rena, 2011; Somerville, 2001). They are also a direct measure of urban policy. In fact, building codes and

1 For a critical survey, see Carson (2010), Dinda (2004) and Kaika and Zervas (2013a, 2013b). 2 Panayotou (2003) presents a thorough summary of empirical studies. 
permits are under the public control. Therefore, the selected indicator may accounts for public environmental concern and policy.

Land (and housing) is a local "stock-sensitive" variable that is subject to saturation effect. All other things being equal, we can therefore expect that once the need for housing is met and income has passed a certain threshold, the positive relationship between income and building permits emission will become negative (through greater environmental awareness and stricter urban planning), confirming the EKC hypothesis. This is so because local externalities are more likely internalized within a single economy or region (Lopez, 1994). When impact has a stock effect, the monitoring of emissions and/or flows is important to determine whether a country is moving towards environmental enhancement (when emissions tend to be below regeneration capacity) ${ }^{3}$ or environmental steady state (when no regeneration is possible).

To test whether the aforementioned relationship holds, we first run a panel data regression model over per capita income and per capita BP. Then, we also test for the cumulative effect of housing, to verify whether a saturation effect emerges. Data are from all the Italian regions. This heterogeneous set enables us to test for fixed effects. The aim is to determine whether environmental considerations tend to prevail over socio-cultural and economic aspects or, rather, considering the multitude of players involved in the real estate market, private and speculative forces prevail over aspirations of environmental conservation. In other words, the aim is to test whether actual choices contradict policy makers’ statements of principles.

\section{Land consumption and the EKC}

Besides being essential for the production of goods and environmental services, land contributes to the production of social goods, such as housing and landscape. Since this limited (and not substitutable) resource is easily destroyed, it is of utmost importance to understand the dynamics of the key determinants of its consumption, in particular, the relationship between land consumption and economic growth.

A central concern of classical economics was the dependence of human and economic activity on its material base, i.e. natural resources. Land, representing natural resources in general, was considered a necessary input to production and an important determinant of growth and wealth. Technical progress, more intensive and extensive production processes, economic development and theoretical (r)evolution made the issue of its limited availability disappear from the theoretical debate (Perman et al., 2011).

3 It has been calculated that the carrying capacity of the Earth's atmosphere, in term of $\mathrm{CO}_{2}$, is 14.5 Gt, whereas current emissions are running at twice this level (UNDP, 2007) 
The huge population growth that followed the industrial revolution and the ensuing urban development, together with desertification induced by intensive land use and climate change, have brought the problem of land and soil scarcity to the attention of the scientific and political community. In particular, attention has been addressed to soil consumption and degradation, and their ecological and productive consequences (JCR, 2012). The importance of the topic is reflected by the Africa Consensus Statement to Rio+20: “The time is ripe to agree on a new sustainable development goal at Rio+20 for zero net land degradation to secure the continuing availability of productive land for present and future generations” (UNCCD, 2012).

Urban development is one of the most risky land use changes. Unlike other changes, such as agriculture, it causes soil sealing that is permanent or very difficult, expensive and slow to reverse (EEA and JCR, 2006). Urbanization is the ultimate form of "soil consumption” (EEA and JCR, 2010). Like other forms of soil degradation, it is closely related to economic activity. Here, however, we only consider soil loss induced by urbanization.

According to EEA estimates, Italy lost 87,240 ha and 48,294 ha in 1990-2000 and 2000-2006, respectively (Prokop et al., 2011), mainly due to residential (over 60\%) and industrial-commercial constructions (about 30\%). ${ }^{4}$ Historically, the growth of cities and almost all human settlements has been determined by population and more recently by household number increase. ${ }^{5}$ This, together with better economic conditions and the initial housing stock, has led to restoration and increase in the supply of new houses. If houses were "merely" a place to live (as they have long been), we would expect that after a period of expansion, the fulfillment of housing needs, the shrinking of developable land and the surge in environmental opportunity cost would cause a reduction in BP emission. An EKC would emerge and the result would be a steady state (constant stock) with an investment equal to $\delta$, i.e. the depreciation rate. This would also be justified by a decrease in the population growth rate.

According to the stock-flow equation, the total area of sealed soil $(S)$ at time $t$ is determined as follows:

$$
S_{t}=S_{t-1}(1-\delta)+F_{t}
$$

where:

- $\quad S_{t}$ is the stock, i.e. the cumulated area of sealed soil at time $t$;

- $\quad \delta$ is the restoration rate;

4 The largest land cover category taken over by urban and other artificial land development was agricultural land (about 94\%), while about 5\% was forest.

5 In their study on Italy, Bimonte and Stabile (2015) found, unexpectedly, that housing supply was not related to the number of households in the period analyzed. 
- $\quad F_{t}$ is the flow variable, i.e. the area of soil sealed per year.

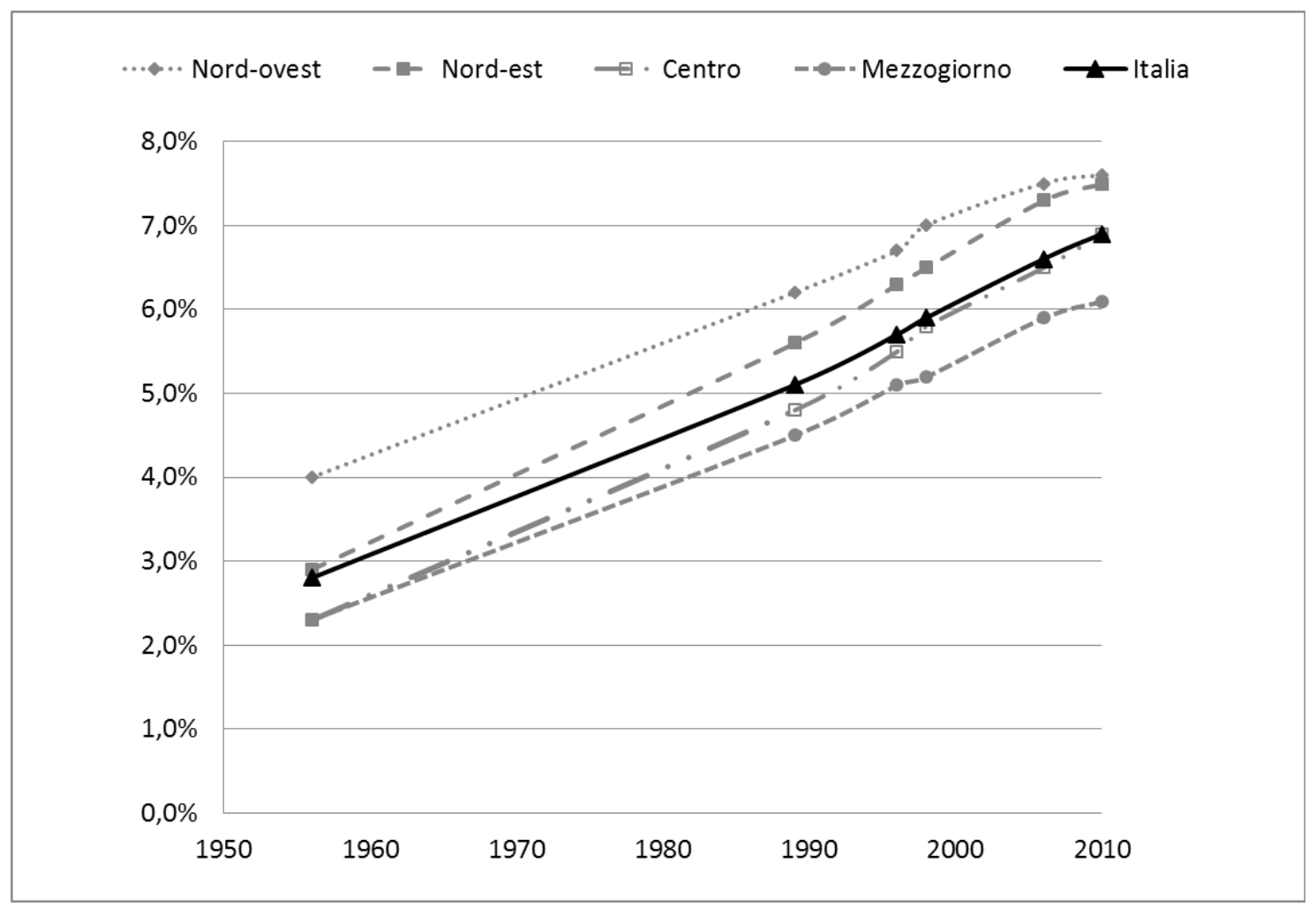

Figure 1: Sealed soil as a percentage of the total area of Italy (1956-2010).

Source: Own elaboration based on Institute for Environmental Protection and Research data (ISPRA, 2014.

Figures 1 shows the evolution of the stock variable (soil consumption) in Italy in the last 60 years. It indicates the area of sealed soil as a percentage of total area, at national and macro-regional levels. It measures soil consumption at six time points: 1956, 1989, 1996, 1998, 2006 and 2010. ${ }^{6}$ As stated before, the main cause of soil loss is urbanization, especially residential construction, that was historically largely determined by economic and population growth. Housing represents the majority of all construction (commercial, industrial), so that sealed soil may be consistently expressed as a function of residential housing, described by the following stock-flow equation:

$$
S_{t}=S_{t-1}(1-\delta)+H_{t s}
$$

where:

- $\quad S_{t}$ is the real estate stock at time t;

- $\quad \delta$ is the depreciation rate;

- $\quad H_{t s}$ is the flow variable, i.e. the number of new constructions.

6 In fact, the situation is even more serious than these figures suggest, as about $35 \%$ of Italy is mountainous and most building and other land transformation has taken place in the plains. 
The area of sealed soil more than doubled in the post war period, and so did the number of houses $(S)$, now exceeding 29 million, many of which are empty (about $1 / 5)^{7}$ or second homes. All other things being equal, $H_{t s}$ depends on market conditions, in particular prices and costs. The higher property prices and the lower building costs, the greater the supply of the new constructions on the market. Another determinant is interest rate, which fosters demand and consequently the supply of real estate assets for dwellings and investment (McQuinn and O’Really, 2008; Di Pasquale and Wheaton, 1994).

However, housing development is also influenced by building codes, zoning laws (Caldera and Johannson, 2013; Green et al., 2005), the length of time it takes to obtain planning permission, its cost and the uncertainty of outcomes (Ball, 2011; Ball et al., 2009; Mayo and Sheppard, 2001; Mayer and Somerville, 2000). In Italy, like in many others places, local government permission is needed in order to develop land and build on lots. The number of BP issued by local authorities may constrain the supply of new houses, placing an upper bound on actual $H_{t s}$. As stated, BP are a good proxy for estimating the supply of housing. In fact, although the issue of permits is not necessarily followed by construction, due to the so-called pipeline effect (Rena, 2011), there is strong evidence of a relationship (Somerville, 2001). Builders respond to new information when deciding whether or not to exercise permits, but it takes large changes in market conditions to generate small changes in permit exercise rates (Somerville, 2001, p. 183). Figures 2 shows the number of annual building permits issued by local governments in the period 1980-2007. Since regions differ in term of population and size, index numbers were used to make data comparable. The base year is 1980. It is worth noting that since the 1980s, Italy has settled into a kind of demographic steady state, with a very low growth rate. A slight increase, mainly due to immigration, has been recorded since 2000. Although differences exist at regional level, this is a shared phenomenon.

These being the main aspects of soil consumption and urbanization at national and regional level, in the next section we present and discuss the results of our empirical analysis.

7 In a recent article (February 2014), The Guardian denounced the "scandal” of empty properties in Europe http://www.theguardian.com/society/2014/feb/23/europe-11m-empty-properties-enoughhouse-homeless-continent-twice 


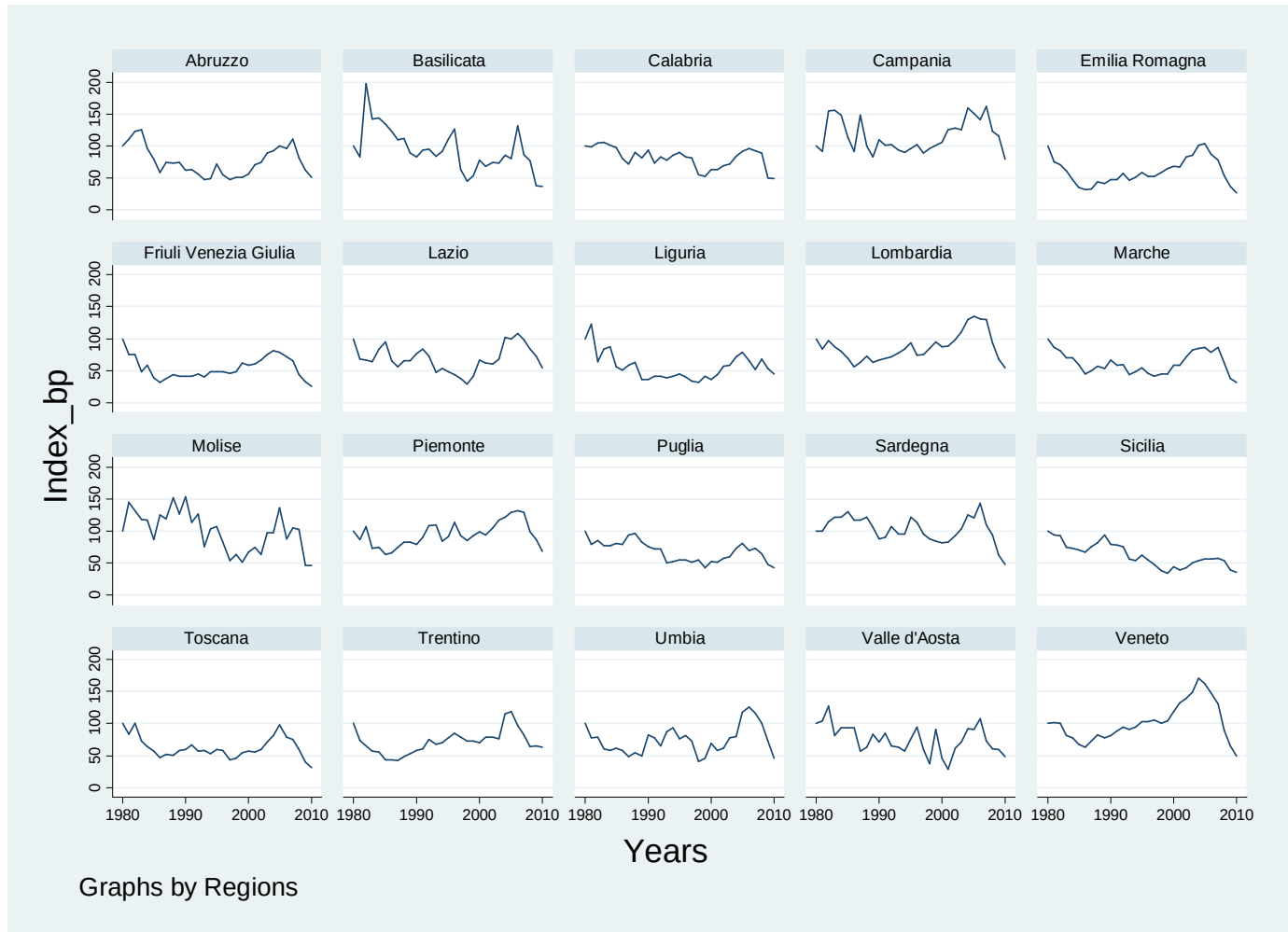

Figure 2: Number of permits issued at regional level $(1980=100)$.

Source: Own elaboration on National Institute of Statistics (ISTAT) data

\section{Land and income: testing the EKC hypothesis}

The main theoretical underpinning for the EKC are technological innovation and preferences evolution. The former would be brought about by the structural changes accompanying economic growth; the latter assumes that the environment is an income-elastic commodity. In the later stage of development, individuals become more environmentally conscious and can afford to exert political pressure for the enforcement of environmental regulations. This would give rise to policies to internalize environmental externalities (Panayotou, 1995, 2003; Grossman and Krueger, 1995). In our case, this means that because of a higher perceived environmental cost, social pressure leads to stricter urban planning. Moreover, considering the characteristics of the selected indicator, the properties of preferences is more relevant than technological innovation.

In order to detect whether the EKC hypothesis holds, we now run a panel data model between per capita income and per capita supply of new BP. Our aim is to determine whether marginal utility of non-environmental good decreases and the marginal disutility of environmental degradation increases with economic growth. The stronger this process the higher the elasticity of substitution. In other words, our goal is to test whether the social valuation of resources prevails over private valuation, as the EKC hypothesis assumes.

To test the EKC and the Income Elasticity Hypothesis (IEH), we use data on income, population and BP at regional level. The data is from the 20 Italian regions for the period 1980-2008. There are 
various reasons for this choice: first, there is no continuous, reliable and comparable data for a longer period for BP; ${ }^{8}$ second, the period chosen complies with our goal. Indeed, it leaves out the postwar reconstruction phase, the baby and economic boom period (the Italian miracle) and the 1970s (a period of massive interregional migration, especially from south to north and from rural to urban areas, and social policy reforms). The concomitant pressure of postwar demographic growth and internal migrations led to an explosion of urban areas and infrastructural investment (transport, energy). The data also does not include the period of the current economic crisis that began in 2008. As for the indicator that we choose for environmental impact, although narrow and partial, has some useful characteristics: it accounts for the stock effect; unlike other measures, such as pollutant levels, it does not depend on atmospheric conditions; it depends marginally on geographic and technological conditions; it is slightly affected by international trade and displacement effect. Finally, it can be thought of as a direct measure of public environmental concern and local policy. Indeed, urban planning is a prerogative of the public sector. Local government permission is needed to build any type of construction. Thus, urban planning policy must be sufficiently permissive (necessary condition) for residential development to take place ${ }^{9}$.

The sample is comprised of regions in an advanced stage of development, although differences in per capita income exist. As stated, the period considered excludes the economic boom (Italian miracle) following the second world war. Both these aspects reduce the incidence of structural effects on the shape of the EKC (Grossman and Krueger, 1995). This means that economic growth may only influence environmental protection through preference structure and entitlements.

These being the premises, we run the following standard functional form where the logarithm of the indicator (in per capita term) is modeled as a quadratic function of the logarithm of per capita income:

$\ln (Y))_{i, t}^{2}+\varepsilon_{i, t}$
$\ln (B P)_{i, t}=\alpha_{i}+\beta_{1} \ln (Y)_{i, t}+\beta_{2} i$

where:

$B P_{i, t}$ is the number of new Building Permits per capita;

$Y_{i, t}$ is per capita GDP;

8 In 1980, the Italian National Institute of Statistics (ISTAT) modified the data collection system. 9 This is not true stricto sensu. In fact, it is worth noting that in Italy there are many illegal building. Unfortunately, there have been various building amnesties, the most important occurred in 1985, 1994, 2003. 
Panel data analysis was carried out with STATA, and both fixed effects (FE) and random effects (RE) models were estimated. These are the two basic models usually used for analysis of panel data. One of the main difference is about inference. Because of the assumption, FE models do not allow to extrapolate results to other samples of data (they are conditional on the country and time effects in the selected sample of data), while this is not true for RE (Hsiao, 1986; Stern, 2004). The latter treats specific effects as components of the random disturbance. RE can be estimated consistently if individual-specific effects and explanatory variables are not correlated. To test for inconsistency a Hausman (1978) test can be used.

Table 1: Correlated Random Effects - Hausman Test

\begin{tabular}{|c|c|c|c|c|}
\hline \multicolumn{5}{|c|}{ Test cross-section random effects } \\
\hline Chi-Sc & tistic & $\begin{array}{c}\text { Chi-Sq. d.f. } \\
2\end{array}$ & \multicolumn{2}{|c|}{$\begin{array}{c}\text { Prob. } \\
0.6802\end{array}$} \\
\hline \multicolumn{5}{|c|}{ Cross-section random effects test comparisons: } \\
\hline Variable & Fixed Effects & Random Effects & Var(Diff.) & S.E. \\
\hline$\overline{\mathrm{LnY}}$ & 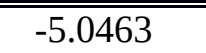 & -5.056644 & ".0103433 & .0190412 \\
\hline$(\operatorname{LnY})^{2}$ & .2701307 & .2707423 & -.0006116 & .0010552 \\
\hline
\end{tabular}

Table 2: Random-effects GLS regression

\begin{tabular}{|c|c|c|c|c|c|c|}
\hline \multicolumn{2}{|c|}{ "Group variable: regions } & \multicolumn{5}{|c|}{$\begin{array}{l}\text { Number of obs }=580 \\
\text { Number of groups }=20 \\
\text { Obs per group: } \min =29\end{array}$} \\
\hline \multicolumn{2}{|c|}{$\begin{array}{ll}\text { R-sq: } & \text { within }=0.2278 \\
& \text { between }=0.0401 \\
& \text { overall }=0.0927\end{array}$} & \multicolumn{5}{|c|}{$\begin{array}{l}\operatorname{corr}\left(\mathrm{u} \_\mathrm{i}, \mathrm{X}\right)=0 \text { (assumed) } \\
\text { theta }=.88013232 \\
\text { Wald chi2(2)=34.36 Prob }>\text { chi } 2=0.0000\end{array}$} \\
\hline $\operatorname{LnBP}$ & Coef. & $\begin{array}{l}\text { Robust Std. } \\
\text { Err. }\end{array}$ & $\mathbf{z}$ & $\mathbf{P}>\mathbf{z}$ & {$[95 \% \mathrm{Co}$} & Interval] \\
\hline $\begin{array}{l}\operatorname{LnY} \\
(\operatorname{LnY} Y)^{2} \\
\alpha\end{array}$ & $\begin{array}{l}-5.056644 \\
.2707423 \\
29.441\end{array}$ & $\begin{array}{l}.9221837 \\
.0501197 \\
4.239507\end{array}$ & $\begin{array}{l}-5.48 \\
5.40 \\
6.94\end{array}$ & $\begin{array}{l}0.000 \\
0.000 \\
0.000\end{array}$ & $\begin{array}{l}-6.864090 \\
.1725095 \\
21.13172\end{array}$ & $\begin{array}{c}-3.2491970 \\
.3689752 \\
37.75028\end{array}$ \\
\hline $\begin{array}{l}\text { sigma_u } \\
\text { sigma_e }\end{array}$ & $\begin{array}{c}.3604306 \\
.23435025\end{array}$ & & Rho & tion of & ance due to $\mathrm{s}$ & $=.7028623$ \\
\hline
\end{tabular}

All this considered we first estimated robust standard errors in FE models. Estimates showed almost no correlation between individual-specific effects and explanatory variables [corr(ui,X)=0.0191]. The F-test also confirmed heterogeneity within units (regions). It rejects the null hypothesis (i.e. that the observed and unobserved fixed effects are equal across all units). Moreover, the variability 
of residuals within groups $\mathrm{u}_{\mathrm{i}}$ (sigma_u=0.35456086) prevailed over that of residuals $\mathrm{e}_{i}$ (sigma_e=0.23435025), as evidenced by the fraction of variance due to individuals (rho=0.695959). Considering previous results, we used a RE model (Hsiao, 1986). Estimates with RE_GLS turned out to be nearly the same as those produced by FE_LSDV (Theta=0.880132) ${ }^{10}$. However, RE estimates proved more satisfactory and efficient, as confirmed by the Hausman test (table 1). The latter did not reject the null hypothesis of no significant difference between FE and RE estimates, as evidenced by the variables' coefficient in table 1 . In order to test for random effects we also run the Breush and Pagan test (Lagrange multiplier). It rejected the null hypothesis that variances across entities is zero. This means that individual effects are important and RE estimates must be used.

Table 2 presents the main estimates. The results are robust, as confirmed by all the diagnostic tests. The model shows that all the estimates are consistent with its hypothesis, as highlighted by the Wald test, for the RE model. As for the coefficients of the variables, we can observe that all are highly significant. Since the function is in the log form, coefficients represent percentage variations and its derivative is the elasticity.

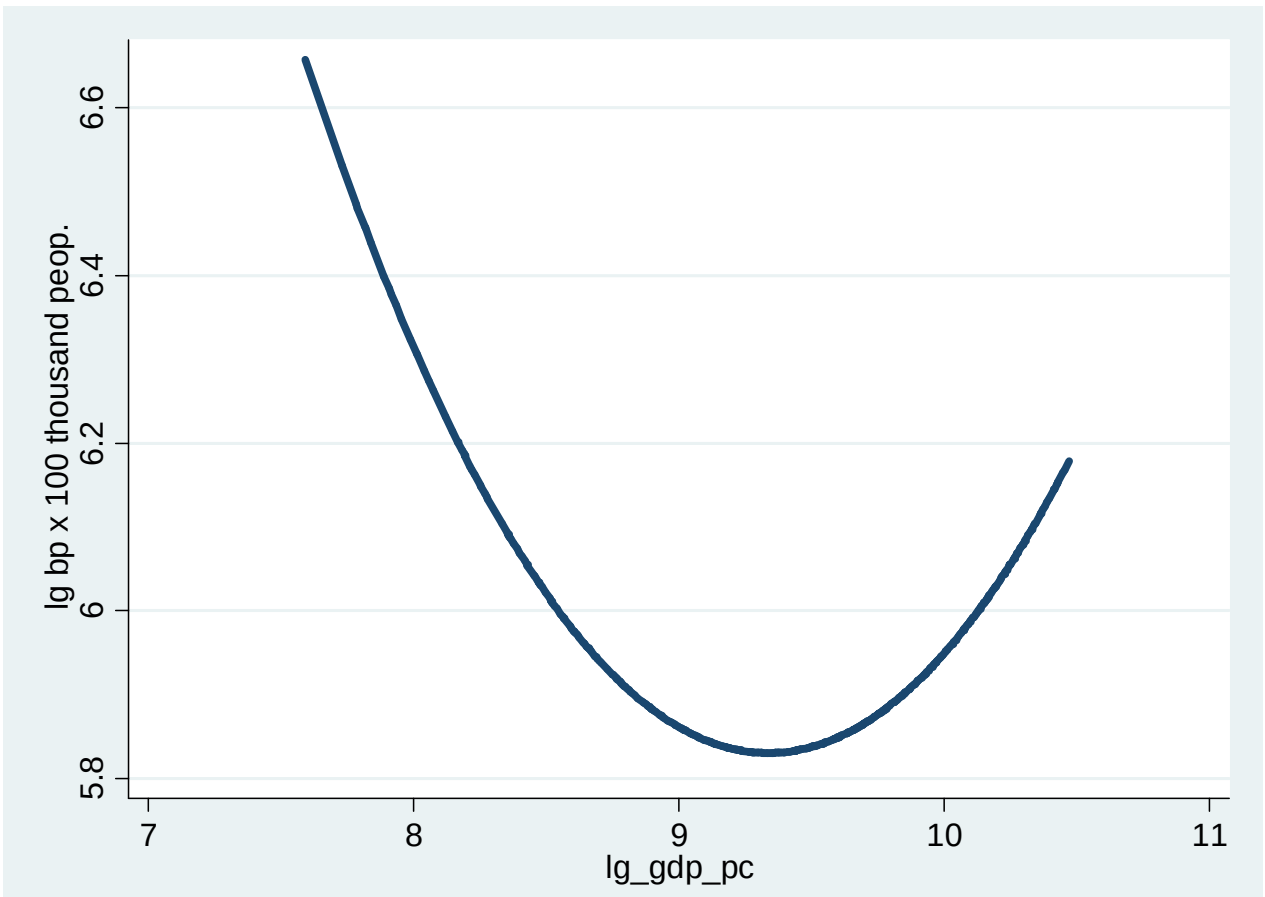

Figure 3: Relationship between housing supply and income (per capita data).

Contrary to expectations, the main stylized fact emerging from the regression is that the relationship between per capita income and conservation of environmental resources, as expressed by the selected indicator, follows a U-shaped path $\left(\beta_{1}<0 ; \beta_{2}>0\right)$. Unlike the EKC, the relationship showed 10 When is close to 1 the RE and FE estimates tend to coincide. This happens when is greater than , i.e when there is heterogeneity. 
that in the first phase the saturation effect prevails but then, once income passes the threshold level, income growth is coupled with increasing land consumption, as proxied by the number of BP issued by the public authority. This means that in the later stage of development, private assessment of resources prevailed over social assessment, i.e. preferences shifted from public to private goods, with detrimental effects on resource conservation. In other words, in the case of land the IEH does not hold. On the contrary, the elasticity increases with income: it is negative at a low level of income and becomes positive when income overcomes a threshold level. Figure 3 evidences this effect, being per capita income and building permits expressed in the logarithms.

To take in due consideration the saturation effect, we also run the following regression:

$$
\begin{gathered}
\ln (Y))_{i, t}^{2}+\beta_{3} \operatorname{Ind}_{B P i, t}+\varepsilon_{i, t} \\
\ln (B P)_{i, t}=\alpha_{i}+\beta_{1} \ln (Y)_{i, t}+\beta_{2} i
\end{gathered}
$$

where Ind_BP $P_{i, t}$ is the fixed base index $(1980=100)$ of the cumulative number of new BP. As for the previous regression, estimates with RE_GLS turned out to be nearly the same as those produced by FE_LSDV (Theta=0.88689), and RE estimates proved more satisfactory and efficient. Table 3 presents the main estimates of the regression.

Table 3: Random-effects GLS regression

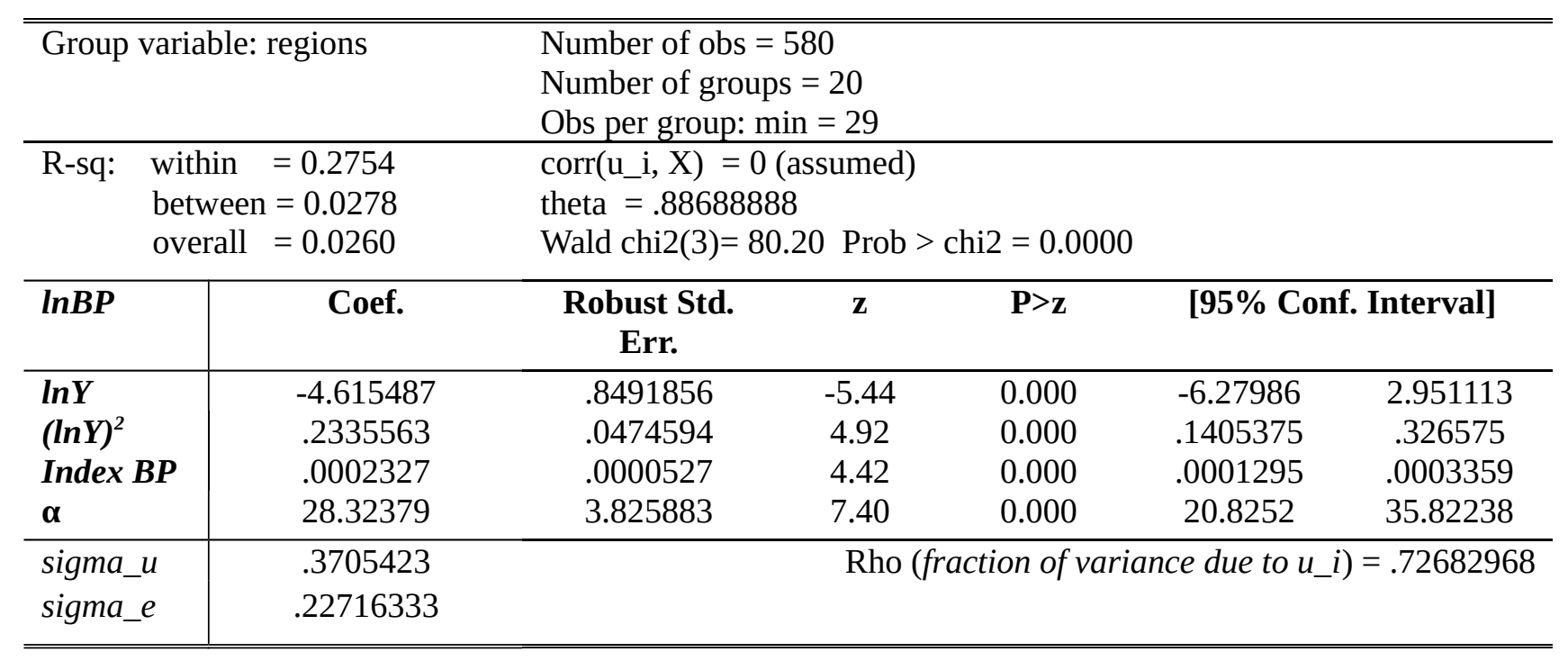

Once again, the results are very sound, as shown by all the diagnostic tests. As it can be seen, instead of the saturation effect an imitation effect seems to prevail. In fact, although small, $\beta_{3}$ is a positive number. It means that the greater the stock (i.e. developable land) the greater the flow (i.e. new BP). This is the typical results of strategic interactions on public or common goods. In these 
cases individual rational provokes a social tragedy. The novelty is that in our case it can emerge both at the individual and municipality level.

\section{Discussion}

A possible interpretation of our results may be as follows. As expected, a slowing of the housing sector followed the economic and infrastructural boom of the 1970s, the demographic increase and the wave of internal migration. Private and public investment were mainly aimed at fulfilling housing needs (family homes) and houses were mainly to live in or for vacations. The share of home-ownership steadily increased from the 1970s, reaching about $69 \%$ by 1998 . This was a consequence of economic growth and redistribution policies. The building slowdown was also a consequence of a slowing in the growth rate of the Italian population, which remained more or less stable, and the saturation effect. Almost all regions experienced the same population dynamics, although with differences. The decreasing trend implies that the emission of BP decreased comparatively more than population.

This is consistent with expectations. Additional economic growth would reinforce the negative relationship. In fact, the IEH would cause environmental awareness to increase. This, together with a higher environmental opportunity cost, would determine stricter urban planning aimed at meeting dwelling needs at the lowest social (environmental) cost.

Unfortunately, according to our results, the expected shift of preferences from private to public goods was short-lasting. Around the first half of the 1990s, the negative relationship between per capita income and BP (land consumption) became an expansive cycle: beyond the turning point, further economic growth widened the gap between private and social appraisal of environmental resources. Obviously, depending on their income level, regions passed this threshold in different years.

Together with other socio-cultural phenomena, this stylized fact was fostered by greater availability of funds, derived from the combined effect of income growth and low interest rates. Better economic conditions gave rise to a different concept of house. It became a positional good and an investment (a haven asset during economic crises and a speculative or portfolio management investment in periods of economic growth) rather than merely a place to live.

As stated before, housing development is under public control. In particular, building codes and zoning laws are under the jurisdiction of local authorities, who decide how many building permits to issue. An expansive cycle can only take place with accommodating urban policy. This also implies that local government preferences shift from social to private goods and from long- to shortrun objectives, with detrimental overall effects on welfare. 
According to Bimonte and Stabile (2015), this is what happened in Italy as a consequence of the liberalization and decentralization process that started in the 1990s, with some degree of deregulation, reduced central government transfers to local authorities and expansion of fiscal autonomy. Budgetary needs prompted many local authorities to use their taxing power to finance their current expenditure. Since the fiscal reform of 1993, the Italian property tax (ICI) has been the main source of revenue for local government. ${ }^{11}$ Exploiting the upward cycle of the real estate market, municipalities presumably adopted more accommodating urban planning policies to compensate for their increasing budgetary needs. In fact, besides ICI, they could also levy an una tantum impact fee on new or proposed development projects. Unfortunately, most Italian municipalities used both these tax revenues to finance their current expenditure, laying the foundations for future economic, and especially environmental, deficits (Ihlanfeldt and Mayock, 2014).

Instead of maximizing intertemporal social welfare, citizens and their representatives maximized their short-term interests. Unfortunately, actual facts do not always conform to theory. Land has become a monofunctional resource that is (over)exploited to extract private rent and revenues for the public sector. The former mainly accrues through increases in land prices, the latter through various land-related taxes and fees. These taxes are rarely applied to internalize the external costs generated by land use. In fact, land use changes, and in particular changes in land cover, strongly influence soil ecosystem functions, such as the water cycle and carbon storage, as well as landscape. Construction is effectively decoupled from any ecological, environmental or social consideration.

The inverted EKC is the result of an apparent "win-win" game where economic, institutional and political elements intermingle. In Italy, housing has always been a sensitive topic that affects many people. The massive involvement of players suggests why individuals (society) on one side and public authorities on the other favor private over social goals and overrate present benefit to detriment of future social costs.

The inverted EKC is also the result of a strategic interaction. Although privately owned, land (and landscape) has the characteristics of commons or public goods, as well as representing a good whose utilization produces externalities. Only a cooperative or regulatory (coercive) approach may prevent overexploitation. But, because of the abovementioned aspects, and since benefits (financial and political) accrue in the present while costs will be born in the future, both failed.

11 ICI is an annual levy. Its taxable base is the cadastral rental value of the property (valore catastale), a statutory value assigned by the Government. The current property valuation system is based on estimates of market rental values from 1988-89. Though revised, the cadastral value is generally substantially less than and not related to actual market prices. ICI tax revenue is therefore decoupled from house market prices. In 2008 the Italian government abolished ICI on the main family home. 


\section{Conclusions}

The empirical status of the EKC hypothesis is a very important issue, because its acceptance may have major policy implications. If the EKC hypothesis held in general, it would imply not only that economic growth is "decoupled" from environmental deterioration, but also that growth is the means to environmental enhancement (Beckerman, 1992). In the long run, it would also imply cross-country convergence in terms of environmental quality (Bimonte, 2009; Brock and Taylor, 2004; List, 1999).

Many authors have questioned this. Empirical evidence shows that what happens depend on countries and indicators. Particular attention also has to be paid to indexes, because overall environmental impact and quality depend on aggregates, rather than on per capita or per unit of income impacts, and on stocks rather than flows (Bimonte, 2012). Except for cases in which per unit or per capita environmental impacts eventually fall to zero, the results are not straightforward. In fact, if per capita or per unit environmental impacts converge to a very low level, different from zero, in the long run the total impact increases with increasing population or income (Common, 1995). This aspect is even more important when variables are characterized by stock effects, as in the case of housing and consequently land.

Considering these concerns, many authors have cautioned against any simplistic inference, such as all we need is growth (Beckerman, 1992). Grossman and Krueger (1995) allege that it would be incorrect to believe that the process is automatic, even in cases where an EKC seems to exist. Arrow et al. (1995) reinforce this statement, concluding that economic growth is not a panacea for environmental quality, and policies that promote economic growth are not substitutes for environmental policy.

Our results provide additional support for these claims. When we used the emission of BP (and housing) as a proxy for land consumption, our estimates surprisingly showed an inverted EKC. In fact, the IEH holds for developable land (housing) rather than for environment. In others words, as income grows and passes a certain threshold, environmental conservation becomes less important than land development, and private benefits outweigh social costs. Social preferences shift away from social towards private goods, from long- to short-run goals. This is consistent with the results of other studies on land degradation in Italy (Salvati and Zitti, 2008; Smiraglia et al., 2016) Why this happens is an intriguing question, worthy of further research. Drawing on Bimonte and Stabile (2015), our hypothesis is that the combined effect of economic, social and institutional/political factors determines a boost in the housing sector to the detriment of social interest. Income growth and low interest rates largely foster the housing sector. Greater availability 
of funds sustains the demand for houses to live in but also for investment and speculation. The latter may be induced by less equitable growth, as in the recent economic period.

However, this is made possible by accommodating planning policy. The deregulation and decentralization process that started in the 1990s in Italy may have stimulated many local authorities to use their taxing power to finance their current expenditure. In fact, fiscal reform made ICI and impact fees the main tool by which municipalities could increase local revenues. Municipalities may have adopted more accommodating urban planning policy to compensate for their increasing budgetary needs. In the short run, and from a strictly private perspective, this would have been a fruitful strategy.

Our results lead to significant conclusions. The belief that per capita income is the only explanatory variable may be dangerous for several reasons. The empirical results on EKC demonstrate that there is no easy and automatic path to sustainable development. Like Kuznets in his influential work, we strongly believe that effective work in this field calls for a shift from market economics to political and social economics (Kuznets, 1955). However, our results demonstrate that the assertion that environmental enhancement is always the result of the combination of economic factors and public policy may not be true. Indeed, land management is a key policy of public authorities, normally local government. The latter's actions may be determined by how costs and benefits are distributed between players and lobbies (Thompson, 2014). Thus, when private benefits as opposed to social costs are widespread, what is needed are "good” policies and independent institutions. In these cases, exogenous norms should create ties that commit policymakers to a longer-term perspective. Like Ulysses, we all know that there is always a Siren singing. Independent institutions and exogenous norms would help to resist a Siren's song that might cause short term desires to triumph over long-term interests.

In fact, the bigger the minority of people benefitting from an action, the stronger institutions need to be. When the ineffectiveness of rules affects general interest, no reaction takes place as long as a big enough minority benefits from it (Di Martino and Vasta, 2015). ${ }^{12}$ When a multitude is involved, accommodating behavior is fruitful from a political/electoral point of view.

However, the most important conclusion is that empowering the same authority with responsibility for conflicting policies (in our case urban planning and corresponding fiscal policy) is socially inefficient, particularly the more (intra and intertemporal) external effects and public goods are involved. When a potential for conflicting interests exists, rules have to be clear and the institutions independent. In the specific case, it means that the convenience of leaving urban planning and the power to levy property taxes under the same jurisdiction needs careful (re)consideration.

12 They offer the example of Italian soccer scandals. 
To conclude, unlike Beckerman (1992), we do not simplistically infer that "all we need is to degrow”, but when social and intergenerational aspects are involved a balanced mix of market, policies and institutional architecture is needed. This is at the core of the zero net land degradation proposal (UNCCD, 2012). Land is a necessary (but limited) input for all human activities and a stock-sensitive resource. Increasing exploitation reduces its overall quality and the quantity available. The only sustainable option could be consumption (flow) converging to zero or to the appreciation (depreciation in the case of housing) rate $(\delta)$. Any other solution produces (cumulative) soil consumption. We should commit to this result. Unfortunately, the facts confirm that sympathy for certain goals does not translate into acceptance of the costs and sacrifices that actual application may entail. The OECD maintains that in assessing a country's environmental performance, a clear distinction needs to be made between intentions, actions and results (Avérous, 1997). In the Italian case, it seems that facts contradict intentions, i.e. stated and revealed preferences do not converge. Evidently, in order to generalize our results, we are aware that more in-depth analysis is required. In particular, we think that surveys' campaign could provide additional insight on people's preferences and behavior. Nevertheless, our aim was to stimulate reflections on a very debated and engaging subject, not provide incontrovertible interpretations. Considering the robustness of the estimates and diagnostic tests, we think that this result has been achieved and the analysis could constitute a starting point for more exhaustive studies. However, because each country has its own specificities, further research is required to test for different types of relationship. To such aim, we believe that it would be worth exploring this line of investigation further, by replicating this study using different settings, i.e. countries at different stages in the development process and with different environmental awareness.

\section{REFERENCES}

Arrow, K., B. Bolin, R. Costanza, P. Dasgupta, C. Folke, C. S. Helling, B.-O. Jansson, S. Levin, K.G. Mailer, C. Perrings and D. Pimental, (1995). Economic growth, carrying capacity, and the environment. Science, 268(28), pp. 520-521.

Aşici, A.A. and Acar, S. (2016). Does income growth relocate ecological footprint? Ecological Indicators, 61, pp. 707-714

Avérous, C.P., (1997). Assessing environmental performance, in M. Yakowitz (ed), Sustainable development: OECD policy approaches for the 21st century, Organisation for economic cooperation and development, Paris

Bagliani, M., Bravo, G., Dalmazzone, S., (2008). A consumption-based approach to environmental Kuznets curves using the ecological footprint indicator. Ecological Economics, 65 (3), pp. 650661. 
Balaguer, J. and Cantavella, M. (2016). Estimating the environmental Kuznets curve for Spain by considering fuel oil prices (1874-2011). Ecological Indicators, 60, 853-859

Ball, M. (2011). Planning delay and the responsiveness of English housing supply. Urban Studies, 48: $349-362$

Ball, M., P. Allmendinger and C. Hughes (2009) Housing Supply and Planning Delay in the South of England. Journal of European Real Estate Research, 2(2), pp. 151-169.

Beckerman, W. (1992). Economic growth and the environment. Whose growth? Whose environment? World Development, 20(4), pp. 481-496.

Bimonte, S. (2002). Information access, income distribution, and the Environmental Kuznets Curve', Ecological Economics, 41(1), pp. 145-156.

Bimonte, S. (2009). 'Growth and Environmental Quality: Testing the Double Convergence Hypothesis', Ecological Economics, 68(8-9), pp. 2406-2411.

Bimonte, S. (2012). Public goods, environmental quality and the EKC: The "unsaid” of the intensity of use indices, International Journal of Sustainable Economy, 4(2), pp. 167-180.

Bimonte, S. and Stabile, A. (2015). Local taxation and urban development. Testing for the sideeffects of the Italian property tax, Ecological Economics, 120, 100-107

Brock, W. A., and Taylor, M. S. (2004). The Green Solow Model. Working Paper 10557. Natural Bureau of Economic Research, Cambridge, Mass.

Caldera, A. and Johansson, $\AA$ (2013). The price responsiveness of housing supply in OECD countries. Journal of Housing Economics, 22(3), 231-249.

Carson, R.T., (2010). The environmental Kuznets curve: seeking empirical regularity and theoretical structure. Rev. Environ. Econ. Policy, 4(1), pp.3-23.

Caviglia-Harris, J. L., Chambers, D. and Kahn, J. R., (2009). Taking the "U" out of Kuznets: A comprehensive analysis of the EKC and environmental degradation. Ecological Economics, 68(4), pp. 1149-1159.

Common, M. (1995). Sustainably and policy: Limits to economics. Cambridge University Press, Melbourne

Dasgupta, S., Laplante, B., Wang, H., Wheeler, D. (2002). Confronting the Environmental Kuznets Curve. Journal of Economic Perspectives, 16(1), pp. 147-168.

Di Martino, P. and Vasta, M. (2015). Happy 150th anniversary, Italy? Institutions and economic performance since 1861. Enterprise \& Society, 16(2), pp 291-312.

Di Pasquale, D. and Wheaton, W.C. (1994). Housing market dynamics and the future of housing prices. Journal of Urban Economics, 35(1), 1-27.

Dinda, S. (2004). Environmental Kuznets curve hypothesis: a survey. Ecological Economics, 49(4), pp. 431-455. 
EEA and JCR (2010). The European environment: state and outlook 2010. Land use. European Environmental Agency, Copenhagen.

EEA and JRC, (2006). Urban Sprawl: the ignored challenge, EEA report $\mathrm{n}^{\circ} 10 / 2006$, European Environmental Agency and Joint Research Centre, Copenhagen.

Green, R., Malpezzi, S. and Mayo, S.K. (2005). Metropolitan-Specific estimates of the price elasticity of supply of housing, and their sources. The American Economic Review, 95(2), 334339

Grossman, G.M. (1995). Pollution and growth: what do we know? In: Goldin, I. and Winters, L.A. (eds), The economics of sustainable development, (Ch. 2), Cambridge University Press.

Grossman, G.M. and Krueger, A.B. (1995). Economic growth and the environment. Quarterly Journal of Economics, 110(2), pp. 353-378.

Grossman, G.M. and Krueger, A.B. (1996). The inverted U: what does it mean? Environmental Development Economics, 1(1), pp. 119-122.

Harbaugh, W., Levinson, A., Wilson, D.M., (2002). Re-examining the empirical evidence for an environmental Kuznets curve. Review of Economics and Statistics, 84(3), pp. 541-551.

Hausman, J. A. (1978). Specification tests in econometrics. Econometrica, 46, 1251-1271.

Hsiao, C. (1986). Analysis of Panel Data. Cambridge University Press, Cambridge.

Ihlanfeldt, K.R. and Mayock, T. (2014). Housing bubbles and busts: The role of supply elasticity. Land Economics, 90(1): 79-99.

ISPRA (2010). Annuario dei dati ambientali, Istituto Superiore per Protezione e la Ricerca Ambientale, Roma.

ISPRA (2014). Rapporto sul consumo del suolo in Italia. Istituto Superiore per Protezione e la Ricerca Ambientale, Roma.

JCR and EC (2012). The state of soil in Europe. Luxembourg, Publications Office of the European Union.

Jedwaba, R. and Vollrathb, D. (2015). Urbanization without growth in historical perspective. Explorations in Economic History, 58, 1-21.

Kaika, D. and Zervas, E. (2013a). The Environmental Kuznets Curve (EKC) theory — PartA: Concept, causes and the CO2 emissions case. Energy Policy, 62, 1392-1402.

Kaika, D. and Zervas, E. (2013b). The environmental Kuznets curve (EKC) theory. Part B: Critical issues. Energy Policy, 62, 1403-1411.

Kearsley, A. and Riddel, M. (2010). A further inquiry into the pollution haven hypothesis and the Environmental Kuznets Curve. Ecological Economics, 69, 905-919.

Kriström, B. and Riera, P. (1996). Is the income elasticity of environmental improvements less than one?”, Environmental and Resource Economics, 7(1), 45-55. 
Kuznets, S., (1955). Economic growth and income inequality. American Economic Review, 45, 128.

List, J.A. (1999). Have air pollutant emissions converged among U.S. regions? Evidence from unit root tests. Southern Economic Journal, 66(1), pp. 144-155.

Lopez, R. (1994). The environment as a factor of production: the effects of economic growth and trade liberalization. Journal of Environmental Economics and Management, 27(2), pp. 163-184.

Magnani, E. (2000). The Environmental Kuznets Curve, environmental protection policy and income distribution. Ecological Economics, 32(3), pp. 431-443.

Mayer, C.J. and Somerville, T. C. (2000). Land use regulation and new construction. Regional Science and Urban Economics, 30, 639-662

Mayo, S. \& Sheppard, S., (2001) Housing Supply and the Effects of Stochastic Development Control, Journal of Housing Economics, Elsevier, vol. 10(2), 109-128.

McConnell, K. (1997). Income and the demand for environmental quality. Environment and Development Economics, 2, 383-400.

McQuinn, K. and O'Reilly, G. (2008). Assessing the role of income and interest rates in determining house prices. Economic Modelling, 25, 377-390

Munasinghe, M. (1999). Is environmental degradation an inevitable consequence of economic growth: tunnelling through the environmental Kuznets curve. Ecological Economics, 29(1), pp. 89- 109.

Panayotou, T. (1995). Environmental degradation at different stages of economic development. In: Ahmed, I. and Doeleman, J.A. (eds), Beyond Rio. The environment crisis and sustainable livelihoods in the third world, (pp. 45-67), MacMillan Press Ltd.

Panayotou, T. (2003). Economic growth and the environment. Economic Survey of Europe, No. 2, United Nations, New York.

Perman, R., Ma, Y., Common, M., Maddison, D. e McGilvray, J. (2011). Natural Resources and Environmental Economics, Fourth Edition, Pearson

Prokop, G., Jobstmann, H. and Schönbauer, A. (2011). Report on best practices for limiting soil sealing and mitigating its effects. European Commission, DG Environment, Bruxelles.

Rena Mourouzi-Sivitanidou (2011). Market analysis for real estate. Edited by Petros Sivitanides

Salvati, L. and Zitti, M. (2010). Regional convergence of environmental variables: Empirical evidences from land degradation. Ecological Economics, 68, pp. 162-168

Selden, T. M. and Song, D. (1994). Environmental quality and development: Is there a Kuznets curve for air pollution? Journal of Environmental Economics and Environmental Management, 27(2), pp. 147-162. 
Shafik, N. and Bandyopadhyay, S. (1992). Economic growth and environmental quality: time series and cross-country evidence. Background Paper for the World Development Report 1992. Washington, DC: The World Bank.

Smiraglia, D., Ceccarelli, T., Bajocco, S., Salvati, L. and Perini, L. (2016). Linking trajectories of land change, land degradation processes and ecosystem services. Environmental Research, 147, pp. 590-600.

Somerville, T. (2001). Permits, starts, and completions: Structural relationships versus real options. Real Estate Economics, 29(1), pp. 161-190

Stern, D.I. (2004). The Rise and Fall of the Environmental Kuznets Curve. World Development, 32(8), pp. 1419-1439

Stern, D.I., and Common, M.S. (2001). Is there an environmental Kuznets curve for sulfur? Journal of Environmental Economics and Management, 41(2), pp. 162-178.

Stern, D.I., Common, M.S., and Barbier, E.B. (1996). Economic growth and environmental degradation: the environmental Kuznets curve and sustainable development. World Development, 24(7), pp. 1151-1160.

Suri, V. and Chapman, D. (1998). Economic growth, trade and energy: implications for the environmental Kuznets curve. Ecological Economics, 25(2), pp. 195-208.

Thompson, A. (2014). Environmental Kuznets Curve for water pollution: The case of border countries. Modern Economy, 5, 66-69.

Torras, M. and Boyce, J.K. (1998). Income, inequality, and pollution: a reassessment of the environmental Kuznets curve. Ecological Economics, 25(2), pp. 147-160.

UNCCD (2012). Zero net land degradation: A sustainable development goal for Rio+20. UNCCD secretariat, Bonn, Germany.

UNDP (2007). Human Development Report 2007/2008. Fighting climate change: Human solidarity in a divided world. United Nations Development Programme, New York.

Unruh, G.C. and Moomaw, W.R. (1998). An alternative analysis of apparent EKC-type transitions. Ecological Economics, 25(2), pp. 221-229.

World Bank, (1992). World Development Report 1992: development and the environment. The World Bank, Washington, DC.

York, R., Rosa, E.A., Dietz, T. (2004). The ecological footprint intensity of national economies. Journal of Industrial Ecology, 8(4), 139-154. 


\title{
Land consumption and income in Italy
}

\section{A case of inverted EKC}

\author{
Salvatore Bimonte ${ }^{a}$ e Arsenio Stabile ${ }^{b}$ \\ aUniversity of Siena, Department of Economics and Statistics \\ bUniversity of Siena, Department of Business and Law
}

\begin{abstract}
The EKC hypothesis postulates that the relationship between economic growth and environmental deterioration is represented by an inverted $U$-shaped function. Its validity has been questioned from several perspectives and a need for public policies has been expressed. This paper uses a heuristic approach to analyze the relationship between per capita income and land consumption, as proxied by the number of Building Permits issued by public authorities. Using data from the Italian regions, we run a panel data regression model to test whether the EKC hypothesis holds. Results confute it, evidencing a U-shaped relationship. In the authors' opinion, the combined effect of market conditions, lifestyle evolution and institutional and political factors have produced an adverse effect on environment. On this basis, the paper claims that, when social and intergenerational aspects are involved, a balanced mix of market, policies and institutional architecture is needed.
\end{abstract}

Keywords: Environmental Kuznets Curve, economic growth, land use, soil sealing, housing.

JEL Classification: C23; H71; Q24; Q56; R31; R38.

\section{Corresponding Author:}

Prof. Salvatore Bimonte

Dipartimento di Economia Politica e Statistica

Piazza S. Francesco 7, 53100 Siena (Italy)

Phone: +39-0577-233053

Fax: +39-0577-232661

E-mail: bimontesalvatore@gmail.com 


\section{Revision for ECOLEC_2016_211}

Title: Land consumption and income in Italy: A case of inverted EKC

Journal: Ecological Economics Comments from the editors and reviewers:

\section{Dear reviewers,}

First of all, we want to thank you for the support and detailed comments, which have assisted us greatly in preparing a revision of our paper. We hope that we succeeded in addressing all the comments and that the new version fulfil your requirements.

Sincerely yours

\section{Response to the reviewers' comments}

Comments are repeated in italics and responses (R) are presented for each point.

\section{Reviewer 1}

This study investigate the relationship of land consumption and income using Italy as the study case. Though the study does not fall entirely in my expertise area, I found it is interesting to read and the case of inverted EKC is intriguing. Putting the findings of the current study in the general context of sustainable urban development will be valuable not only to the area of environmental economics but to many related scientific and engineering communities. Overall, the paper is well written, the method solid, and the results interesting. I therefore recommend its publication.

(R) - Thanks for your encouraging comments.

\section{Reviewer 2}

In our opinion, the paper can be transformed into a short paper - research note of maximum 10-12 pages, by dropping tables and figures that are not necessary (for example, Figure 6, the Appendix, etc)

(R) - We took in due consideration this requirement and revised the paper accordingly. In particular, we cancelled out the appendix, some figures and, whenever possible, text (just some sentences). Details in what follows. As for the transformation in a research note, we think that the journal's aim and target, together with the argument the paper deal with, would not suggest it. Moreover, according to the guide for author, manuscripts should fall into one of five categories: News and Views, Commentary, Surveys, Methodological and Ideological Options or Analysis. The latter seems the most appropriate. The paper is well below the maximum length.

\section{The following suggestions could be used to improve the manuscript:}

Abstract is too long. Just include description of the research problem, the methodology and data and the main results of the study.

(R) - We did it. 
Include JEL codes

(R) - We added it.

Figure 1 is of poor quality.

(R) - We tried to improve the quality. We hope that it is better now.

Figure 2 do not shows the dynamics. It is only a comparison between two years. And you didn't include a comment on this figure.

(R) - We changed the word "dynamics" with "evolution" and eliminated figure 2. As for the explanation, on page 6 the following paragraph tries to explain it: "Figures 1 shows the evolution of the stock variable (soil consumption) in Italy in the last 60 years. It indicates the area of sealed soil as a percentage of total area, at national and macro-regional levels. It measures soil consumption at six time points: 1956, 1989, 1996, 1998, 2006 and 2010".

The same comment for almost all the figures: if you include a figure, you must comment the facts that can be deduced from the figure. If not, eliminate the figure.

(R) - We cancelled out figure 3. The old figure 4 is now figure 2. On page 6 we explained it as follows: "Figures 2 shows the number of annual building permits issued by local governments in the period 19802007. Since regions differ in term of population and size, index numbers were used to make data comparable. The base year is 1980".

In particular Figure 6 can be excluded.

(R) - In general, we agree with the reviewer. However, considering that "The journal is transdisciplinary in spirit" and that its audience is made up of people of different disciplines and background, we think that it may be of some help for understanding.

Please include a reference to similar papers using the same methodology to study the EKC hypothesis. These references must be used in the conclusions section to compare with your results.

(R) -To the authors' knowledge, no other paper exists on the same subject. While a plentiful literature exists on the EKC (the most important papers are cited in the references), there are no other study on the relationship between land consumption and income. There is a study at the Italian level on Land Degradation but it does not fall within the EKC approach. However, we quoted it.

Please include also other references different from Bimonte et al for the Italian case (it seems that there are too many auto-references)

(R) - See previous point. However, only 1 out of 4 of Bimonte et al.'s articles refers to Italy, and this is exactly for the abovementioned reasons. 
Please control that any reference cited in the text is included in the References list and conversely

(R) - We did it. We are sorry about that and hope that now is ok.

There are two "Table 3" and there are no comments about the results showed in these tables. Is it necessary to include them as part of the manuscript?

(R) - We modified a little this part and inserted reference to tables.

Appendix and most of the tables and figures can be dropped, and probably included as complementary material that can be consulted in a web page.

(R) - As stated before, we deleted the appendix, table 3 and three figures (2, 3 and 5), together with part of the text.

Please include the limitations of your research. Include also future developments of this line of research.

(R) - We insert a short paragraph at the end of the paper. 


\section{Highlights}

We test the EKC for land consumption as proxied by new housing supply.

The paper evidenced that in the case of land an inverted EKC emerges.

We allege that effective work in the environmental field calls for public policies.

We evidence that widespread private interest may cause public policy to fail.

Environment asks for a balanced mix of market and institutional architecture. 


\section{Revision for ECOLEC_2016_211}

Title: Land consumption and income in Italy: A case of inverted EKC

Journal: Ecological Economics Comments from the editors and reviewers:

\section{Dear Editor,}

First of all, we want to thank you and the anonymous reviewers for the support and detailed comments, which have assisted us greatly in preparing a revision of our paper. We hope that we succeeded in addressing all the comments and that the new version fulfil your requirements.

We gave due consideration to all comments, which appeared to us not so negative. The only comment that we addressed partially is the one referred to the paper's length. Given the argument and the journal's audience, we think that the transformation in a research note would compromise the paper's aim.

Moreover, according to the guide for author, manuscripts should fall into one of five categories: News and Views, Commentary, Surveys, Methodological and Ideological Options or Analysis. The latter seems the most appropriate. The paper is well below the maximum length.

I hope that you can understand our point.

Sincerely yours

Salvatore Bimonte 